\title{
A Process to Analyze Strategic Design and Management Decisions Under Uncertainty in Complex Entrepreneurial Systems
}

\author{
Mark P. De Lessio ${ }^{1}$, Michel-Alexandre Cardin ${ }^{1}$, Angel Astaman ${ }^{1}$, Valerie Djie ${ }^{1}$ \\ ${ }^{1}$ National University of Singapore, Singapore 117576
}

\begin{abstract}
This paper proposes a process to support strategic design and management of complex entrepreneurial systems under uncertainty. The process is designed to help designers and decisions-makers readily identify valuable opportunities for flexibility as a way to deal pro-actively with uncertainty and improve strategically the lifecycle performance of the system as it is designed, deployed, and managed in operations. The process relies on the novel concept of a layered design structure matrix (DSM), which provides gradually a systems-level representation of the enterprise system starting at an early stage, and gaining more details as more information becomes available about the system and its environment. The resulting layered DSM is used to identify performance-enhancing flexibility strategies in the design and management of the system. The flexibility, providing the "right, but not the obligation, to change the system in the face of uncertainty" provides contingencies to minimize exposure to downside risks, and to enable the system to capture upside opportunities - thereby improving expected lifecycle performance. The process is applied as a demonstration to the analysis of a startup system in the sector of mobility on-demand transportation. Strategic-level opportunities for flexibility are identified systematically, and real options analysis is used to demonstrate quantitatively lifecycle performance improvement as compared to baseline design concepts.
\end{abstract}

Keywords: Entrepreneurial Organization, Design Structure Matrix, Flexibility in Engineering Design, Mobility OnDemand Transportation, Real Options Analysis

\section{INTRODUCTION}

Untested market conditions, regulatory obstacles and changing technology are examples of start-up characteristics that make future system performance and success very challenging over the long term. As such, start-up organizations are typically evolutionary, inherently dynamic in nature and coupled with significant uncertainty. It is the existence of such uncertainty that motivates this work. Categorized as known unknowns, such a state of knowledge suggests a response which consists of adopting a strategy that help minimize the potential impact of not knowing [Lewis et. al. 2014]. With the explicit objective of minimizing downside impacts of such uncertainty and capitalizing on upside opportunities in an entrepreneurial environment, this paper contributes a novel process to help designers and decisionmakers of complex entrepreneurial systems identify explicitly the main uncertainty drivers potentially affecting the future lifecycle performance of their systems. The process aims at generating flexibility strategies to help the system adapt to changing conditions, as a pro-active way to improve such performance. It integrates two powerful methodologies: Change Propagation Analysis (CPA) [Suh, de Weck and Chang, 2007] based on Design Structure Matrix (DSM) modeling [Browning, 2001], and flexibility in engineering design inspired from real options analysis (ROA) in economics and finance [Cardin, 2014, Trigeorgis, 1996, de Neufville and Scholtes, 2011]. It also introduces the novel concept of a layered DSM, which gradually helps decision-makers of a start-up organization acquire and analyze system-level information as it becomes available, generate flexibility strategies as a way to handle uncertainty, and identify the most valuable strategies via quantitative real options and economic valuation.

While it is difficult to categorize uncertainty, in a social system such as an entrepreneurial organization, it can be argued that such uncertainty has both aleatoric and epistemic characteristics. Uncertainty can be aleatoric in that it represents the unknown variability in the system. It can be epistemic in that knowledge can be initially limited [Iaccarino, 2011]. "Sometimes it may be difficult to determine whether a particular uncertainty should be put in the aleatory category or the epistemic category" [Kiureghian and Ditlevsen, 2007]. However, it is difficult to surmise that unknowns associated with entrepreneurial uncertainty simply result from a lack of knowledge when such knowledge will often not become available until an event has occurred. Therefore, the proposed process introduced in this paper 
is limited in its focus on aleatoric uncertainty. Nonetheless, it is, valuable in meeting its objective in enabling a new organization to consider several alternative designs and development plans, so as to ensure the greatest potential for continued growth and long-term viability. Such a process provides new venture stakeholders with the ability to manage and consider gradually the vast amounts of information they are confronted with in a timely and efficient manner in order to make the best strategic decisions for the business.

The case of the Iridium satellite system inspired this effort. It provided an example of an entrepreneurial and complex technological venture that did not account well for uncertainty and flexibility, despite brilliantly functioning technology, and resulted in economic failure. In the 1990s, the sixty-six satellite infrastructure was deployed in space within a year to provide wireless phone communications anywhere on the planet. Market demand did not rise as fast as expected, and the company was not in a position to adapt to changing conditions because the complete infrastructure had been deployed in view of optimistic demand forecasts. Unfortunately, Iridium had to file for bankruptcy in the early 2000s due to insufficient revenues to cover debt payments arising from US $\$ 4$ billion R\&D costs [MacCormack and Herman, 2001]. de Weck et al. [2004] showed later that a flexible strategy relying on phased capacity deployment would have saved up to $20 \%$ in expected lifecycle costs, and perhaps even helped the company survive despite lower demand and revenues than expected. Since then, flexibility has been shown in many case studies as a property of complex systems that can reduce the impact from downside risk exposure (e.g. like buying an insurance), and positioning the system to capture upside opportunities (e.g. like buying a call option on a stock). The net effect quantified in many studies is typically to improve the expected lifecycle performance by 10-30\% compared to standard design and management relying on optimizing a system design to deterministic views of the future [de Weck, Eckert and Clarkson, 2007].

Similarly, this paper relies on a novel and systematic approach to consider flexibility strategies at an early stage. It is useful when the design and decision-making environment of an entrepreneurial system is called to become more complex over time, and fraught with inevitable uncertainty that may jeopardize its success, despite well-functioning technology. The process is unique in that it is considered from an entrepreneurial perspective, as compared to existing methods typically used to represent more mature systems. The question investigated is whether it is feasible to develop a novel process that can capture the dependencies in a new technological venture, recognize the uncertainties affecting its future lifecycle performance, and devising more systematically performance-enhancing strategies to manage uncertainty by leveraging the concept of flexibility in design and management. Furthermore, one wishes to quantify the expected lifecycle performance of the strategies identified to determine which one(s) are the most valuable.

Much has been written in the literature regarding strategy and decision making which are necessarily applied to a multitude of project settings from day to day tasks to large system design and implementation such as a new venture. Rajagopalan et. al. [1993] drew from the many authors proposing decision process models and concluded that a set of factors influence the strategic decision process including environmental attributes such as uncertainty and complexity, organization conditions such as internal power structure and past performance and finally, the differences between decision specific factors themselves such as the impetus and urgency for the decision. Busenitz and Barney [1997] suggested that under conditions of environmental uncertainty and complexity, such as that of an entrepreneurial venture, biases and heuristics can be an effective and efficient guide to decision-making. Khatri and $\mathrm{Ng}$ [2000] found that the use of intuitive synthesis was positively associated with organizational performance in an unstable environment, such as an entrepreneurial company, but negative in that of a stable environment. The Project Management Institute [2013] frequently cites "expert judgment" as a tool for project decision analysis. In fact, many tools have been proposed to assist in strategic decision making. The Project Management Institute [2013] recognizes many such tools which it deems "analytical techniques" and describes as being used to "forecast potential outcomes based on possible variations of projects or environmental variables and their relationships with other variables." They specifically cite regression analysis, grouping methods, causal analysis, root cause analysis and fault tree analysis among others as analytical techniques. While such tools can be informative and particularly effective in establishing a baseline model and recognizing uncertainty, both key steps in the process proposed here, they fall short, on their own, in considering complexity and uncertainty in large systems. As such, this process not only recognizes the ambiguity of making strategic decisions in large complex systems rife with uncertainty but also embraces it by offering a means to measure, analyze and manage it. 
To that effect, the process is applied as a demonstration to the analysis of a start-up company operating in the very dynamic and locally untested market space of Mobility on Demand (MoD) transportation. The system offers shared electric automobile and bicycle services to provide first and last mile transportation. Layered DSM modeling enables users to show the structure of the system in an organized and compact matrix form while still capturing the dependencies between system elements at different stages of the conceptual design effort. Real options analysis enables economic valuation of flexible design concepts, so that the most valuable opportunities can be identified and implemented [Trigeorgis, 1996]. Together, DSM modeling and real options analysis involves investigating the relationship between components and sub-components of the organizational system, and considers opportunities to improve the lifecycle performance of the system by means of flexibility.

The remainder of the paper is structured as follows. Section II describes the process proposed based on layered DSM and CPA analysis, as well as real options analysis. The process is then applied to Company X in Section III and the simulation results (Section IV) are used to discuss the validity and limitations of the work. Conclusions are presented in Section V.

\section{PROPOSED PROCESS AND RELATED WORK}

The proposed process utilizes the five-phase design framework enabling flexibility in engineering design proposed by Cardin [2014] to cast the proposed methodological approach, going deeper in particular into the concept generation part of the process (phase 3). The five phases consist of generating first a baseline design based on standard practice (phase 1), recognizing and modeling uncertainty affecting lifecycle performance (phase 2), generating opportunities for flexibility as a way to handle uncertainty (phase 3), exploring quantitatively the design space for the best flexibility strategies (phase 4), and managing the process throughout the system lifecycle (phase 5). The following sub-sections describe how each phase of the proposed process is modified to suit the needs of an entrepreneurial organization. It also provides an overview of the latest work in each phase, and how the work addresses some of the gaps needed for application to entrepreneurial systems.

\subsection{Baseline Design}

The approach begins by establishing a baseline design that is customized and unique to the organization system under consideration. Rhodes et al. [2009] proposed an enterprise architecture framework that includes eight views including, strategy, policy, organization, process, product, service, knowledge and IT. However, this framework suggests a standard format applicable to any organization system. While many organizational systems do share common high level characteristics, not all organizations are the same and thus limited to the same organizational framework. Reclassifying what Rhodes et. al. [2009] deemed a view as a domain, the enterprise architecture here considers all key domains that shape the unique structure of the organization being analyzed. From this perspective, it is reasonable to treat the different organizational domains as "components" of the larger organization, and thus subject it to Design Structure Matrix (DSM) modeling.

It is useful to construct a descriptive model to better visualize and conceptualize the organizational system. However, while it highlights some high level key relationships within the organization system it lacks detail when describing how the organization functions and interacts both internally and with its wider environment. For this reason, it is useful to consider enterprise architecture frameworks, as stated above, to establish the baseline design of the organization system being evaluated.

\subsection{Uncertainty Recognition}

Having established a baseline design, it is imperative to identify potential sources of uncertainty. Entrepreneurial companies face significant uncertainties from multiple sources (e.g. market, regulations, technology and finance). Changes created by such exogenous sources often result in specific internal system uncertainties as their effect propagates between interdependent system components. Indeed, Danilovic and Browning [2007] suggested that uncertainties stem from the (often flawed) assumptions about the dependencies among system components. Foster [1993] states that "uncertainty is inherent in the future and dealing with that uncertainty is one of the hardest tasks for management", while advocating scenario planning as a means of recognizing potential future uncertainties. He describes a scenario as "a description of a 'possible future' based on a set of mutually consistent elements, within a 
framework of specified assumptions". de Neufville and Scholtes [2011] emphasized the importance of recognizing uncertainty and suggest that "a good way to develop an understanding of the size and shape of the range of uncertainty is to look at previous experience in the same or similar area". Cardin [2014] proposed formal and practical approaches to "quantify, characterize and model" uncertainty resulting in "explicit evaluation of the baseline and upcoming flexible design concepts under uncertainty".

As demonstrated in the next section, the process proposed here introduces a layered analysis and suggests an iterative approach by which DSM methodology and CPA analysis are applied gradually to increasingly detailed views of the enterprise architecture. The high-level model intends to give a quick insight into the behavior of each domain when it experiences changes resulting from both exogenous and endogenous uncertainties, before embarking on a more detailed examination. Subsequent layers further decompose the domains into their sub-elements to construct increasingly detailed but highly uncertain aspects of subsequent lower-level views of the organization. This also speeds up the analysis in an environment where the organization may not be well-structured yet and where information is sparse.

\subsection{Concept Generation}

Acknowledging and identifying uncertainty sources enables the generation of flexible system design concepts. Flexibility generation involves (1) generating strategies in response to major uncertainty sources and/or (2) identifying areas where to embed flexibility in the design. Cardin [2014] stated that a flexible system design concept is typically composed of a strategy and an enabler and defines an enabler as what is done to the physical infrastructure design and management to provide and use the flexibility in operations and a strategy as representing the aspect of the design concept that captures flexibility. In focusing on the greater enterprise, Mikaelian et. al. [2011] introduced the concept of a "tuple" which conceptualizes distinct real option entities including a "mechanism", defined as "an action, decision or entity that enables a real option" and a "type", which is "an action or decision that can be exercised to implement the real option". It is reasonable to compare the characterizations of Cardin and Mikaelian in that each contains an entity that enables a real option (enabler, mechanism) and a response that actually implements a real option (strategy, type). The Mikaelian et al. [2011] approach adopts a holistic approach in identifying candidate flexibilities by considering all of the enterprise domains suggesting that limiting real option consideration to independent enterprise domains "may lead to sub-optimal means of managing uncertainty within enterprises". We consider a similar holistic view here and demonstrate the approach used to generate flexible system design concepts, as summarized in Figure 1.

\subsubsection{Using DSM Methodology to Define Organizational Relationships}

DSM modeling is used to analyze and aid in the design and management of complex systems. While it provides a fairly easy way to identify and visualize the relationships between the various components of a physical product, applying such a technique to a socio-technical system such as an organization is not as obvious. The model needs to consider all the key components, whether characterized as physical or social, that shape the entire structure of the organization. Therefore, as indicated earlier, the process proposed begins by establishing an organization architecture that is customized and unique to the organizational system under consideration. However, unlike hardware products where the physical dependencies have more clearly defined boundaries, each of the high level domains are fairly broad in scope and therefore, the dependencies are more varied in nature. For example, in the case of Company X under study, three types of services are offered including electric car, bicycle and shuttle services. While similar in many ways, each has a unique dependency profile when compared to the other organization domains and their sub-elements. It is, therefore, beneficial to introduce a layered DSM approach that decomposes the higher level domains into their sub-elements to instill more defined borders and thus more accurate dependency analysis. Loch et. al. [2008] suggested that "if complexity and unforeseen influences make tackling the overall new venture model difficult, then decomposing the overall problem into sub-problems can help improve the new venture's success". Understanding dependencies between decomposed organizational domains enables the application of detailed change analysis highlighting more specific areas of uncertainty that may indicate ideal opportunities for flexibility application. 


\subsubsection{Using Change Propagation Analysis (CPA) to Identify Flexibility Enablers}

Change propagation analysis is used to identify areas within the organization that are most favorable for flexibility consideration. Change propagation is described as the process by which a "change to one part or element of an existing system configuration or design, results in one or more additional changes to the system, when those changes would not have otherwise been required" [Eckert, Clarkson and Zanker, 2004]. The application of CPA is inspired by the work of Suh et al. [2007] who used it to identify critical elements in a product design to be made more flexible. Leveraging this methodology, a similar change analysis technique comparing organizational domains is used here. The impact of change to other components caused by change to one component is measured and classified using the Change Propagation Index (CPI). For a particular design component i, $\mathrm{CPI}_{i}$ expresses the difference between the amount of change information $\Delta E_{\text {in }}$ propagating "in" a component from components connected upstream, and the amount of change $\Delta E_{\text {out }}$ propagating "out" to other downstream components. For a system with $n$ components, CPI is calculated as shown in Equation (1):

$$
\mathrm{CPI}_{i}=\sum_{j=1}^{n} \Delta E_{j, i}-\sum_{k=1}^{n} \Delta E_{i, k}=\Delta E_{\text {out }, i-}-\Delta E_{\text {in }, i}
$$

In the equation, $n$ is the number of domains (or elements) in the system; and $\Delta E_{i, j}$ is a binary number $(0,1)$ indicating whether the $i$ th element is changed because of element $j$. Based on Eckert et al. [2004], a system component that receives more changes than it creates $(\mathrm{CPI}<0)$ is called an absorber. A component that receives the same amount of change as it creates $(\mathrm{CPI}=0)$ is called a carrier $(\mathrm{C})$. One creating more change to downstream components than it receives $(\mathrm{CPI}>0)$ is called a multiplier $(\mathrm{M})$. The technique suggests change multipliers as potential candidates to embed flexibility as these elements will generate more changes in other elements when a design or requirement is changed.

In fact, there is some debate regarding whether flexibility opportunities lie within multipliers or absorbers. Koh et. al. [2013] argued that multipliers should be made more robust as a means of limiting change requirements and thus the propagation of change to other elements that are dependent on them. While this sentiment is logical for a product system, it is argued here that in the highly uncertain environment of a social system, such as an entrepreneurial organization, the objective is not necessarily to limit change but instead embrace it and affect change positively, especially as requirements change over time. Therefore, focus is placed on multipliers as sources of flexibility consideration, so when change does occur its impact on the greater organization can be thoroughly considered and applied most effectively.

The CPA methodology is applied to each DSM layer successively. Only elements identified as "multipliers" in higher level layers are considered in more details in subsequent layers. Doing so enables the identification of increasingly specific areas for embedding flexibility, and thus more insights to the potential of flexibility and real option analysis, without the need to go through a full fledge analysis, as done by Suh et al. [2007]. This approach deliberately tradesoff precision for speed. It aims at identifying a few value-enhancing opportunities quickly, while recognizing that some opportunities may be missed. Here, CPA becomes valuable as it extracts and reveals only the relevant components that actually contribute and are affected by uncertainty which is not as apparent when analysis is done on the $1^{\text {st }}$ layer DSM. For example, the 'Stakeholders' domain might be a multiplier in the $1^{\text {st }}$ layer DSM but in the $2^{\text {nd }}$ layer DSM, it could be determined that only the "Engineering team" is actually a strong multiplier.

\subsubsection{Strategy Generation}

Building on the CPA analysis, the multipliers under each affected domain are then considered as primary candidates for identifying strategies for embedding flexibility in the enterprise architecture. Cardin [2014] suggested that a flexibility strategy is necessary to determine how the system will adapt in the face of uncertainty and is related and inter-dependent with enablers which determine the instantiation and management of the flexibility in the design. Trigeorgis [1996] proposed a number of flexibility strategy categories including the options to defer capital investment, strategically stage or phase deployment over time, expand or contract production output, abandon projects, switch use to accommodate different markets and/or invest in R\&D. However, in distinguishing between flexibility "in" and "on" systems Wang \& de Neufville [2004] suggested that the strategies proposed by Trigeorgis for flexibility 
"on" systems are generally applicable to all systems as opposed to strategies for generating flexibility "in" systems which require specific technical engineering knowledge. As such, identifying potential real option strategies often leverages the inherent expertise and experience of current corporate stakeholders and/or benchmarking and examining historical data of similar organizations. Acknowledging this sentiment Cardin et. al. [2013] suggested the use of explicit training and prompting to stimulate creativity stating that "a prompting procedure may help scaffold the thought process systematically". Similarly, the process being proposed here is designed to stimulate the thought process to help stakeholders identify flexibility strategies when faced with strategic decision-making. The layered analysis defines relationships within the organization that may not be obvious, but are perhaps suitable for flexibility considerations thus stimulating creativity in determining the real option strategies that can be considered and the identification of enablers inherent to the organization itself. This is a holistic approach in that all the domains of the organization are initially considered when identifying potential areas of flexibility, however, when identifying specific real options only those sub-domains that indicated flexibility potential are considered further. Such an approach falls in line with the goal of conducting an analysis for enabling better strategic decision making without involving extensive time consuming analytic exercise. This process is designed to drive individual stakeholders to their own conclusion considering multiple domain enablers when identifying and considering real option strategies to address. It leverages the expertise of the individual stakeholders conducting the exercise while triggering broader thought process when they may have a tendency to focus on flexibility enablers and strategies inherent to their own responsibility or organization domain silo.

\subsection{Design Space Exploration}

In this phase the design space for the most valuable system design concepts and decision rules to operate the system are explored. The phase involves using quantitative procedures such as statistical analysis, optimization, and Monte Carlo simulations to evaluate concepts and computational procedures to speed up analysis. Inspired by the method proposed by de Neufville and Scholtes [2011], a simulation modeling technique typically involving four steps is used in this study.

First, a baseline model is developed to assess lifecycle performance, and find an optimal benchmark based on standard design and project evaluation methods. This may rely on discounted cash flow (DCF) analysis, discrete event simulation, queuing, computer-aided design, or others, provided the approach enables quantitative measurement of the expected performance of different alternatives. A suitable metric is selected to quantify the performance, such as Net Present Value (NPV) of cost, vehicle availability, etc.

Second, potential uncertainty sources that are affecting the system in question are introduced into the model using various probability distributions and Monte Carlo simulation. This approach builds upon the deterministic model and modifies its components to incorporate uncertainty and flexibility, enabling real option simulations. Forecast inaccuracy is taken into account while historical trends and potential trend-breakers are studied. The uncertainties introduced are modeled via stochastic modeling and Monte Carlo simulations are subsequently performed to generate multiple scenarios based on a combination of different values for the uncertainties. For example, design and management strategies can be rank ordered based on expected NPV (ENPV) or other metrics.

Third, based on potential opportunities for flexibility identified, flexibility is embedded in the model by altering certain design parameters based on some decision rule(s). The objective is to consider potential flexible designs that can withstand the uncertainties introduced. For example, for Company $\mathrm{X}$, a decision rule may include exiting the bike service should the profit generated from the service fall below a certain threshold. For each flexible design, a decision rule is formulated to dictate how the performance model will behave under different scenarios. Existing parameters in the model are modified and additional ones are added to incorporate the cost and benefit of employing the specific flexibility. Based on simulations, the cumulative probability distribution (CDF) curve of the resulting performance outcomes of each design can be plotted. Various metrics can be used for comparison, such as the mean or expected performance, Value At Risk (VAR) (e.g. the 10th percentile value which quantifies downside potentials), Value At Gain (VAG) (e.g. the 90th percentile to quantify upside potentials), initial capital expenditures (CAPEX), standard deviation, etc. The value of flexibility is then measured by subtracting the expected performance of the best inflexible or standard alternative to that of the best flexible alternative(s). If the difference is positive, then the flexible design is indeed beneficial and the difference is referred to as the value of flexibility. 
Lastly, a sensitivity analyses is conducted to verify the results. de Neufville and Scholtes [2011] caution against human error in parameterizing uncertainties and assert the importance of testing results against changes in input parameters. In some instances, such as when historical data is lacking, the assumed parameter values may be inaccurate. Therefore, a sensitivity analysis is conducted to validate if changes to the assumptions made would lead to different conclusions. Section III demonstrates how the proposed framework is applied to startup organization, Company X.

\section{INDUSTRY APPLICATION}

Company $\mathrm{X}$ has established itself as a complementary service to the public transportation system by providing first and last-mile connectivity - defined as the transportation needed to/from home from/to major transportation hubs (e.g. bus/metro stations). A goal of the organization, which is unique from other players in the transportation sector, is to offer one-way drop off capability without penalty. Current transportation providers typically require customers to return the vehicle to the point of departure or pay an additional fee. Both the electric vehicle commitment and the ability of one-way use demonstrate areas of uniqueness that may impact the relationship between the organization domains and their inherent sub-components, thus influencing specific decision requirements of the organization.

\subsection{Baseline Design}

Table I describes the architecture and unique domains representing Company $\mathrm{X}$. While including similar high level characteristics as other organizations, the architecture is unique to Company $\mathrm{X}$. This reality becomes more pronounced as the high level domains are decomposed into multiple sub elements which become apparent in the $2^{\text {nd }}$ layer DSM analysis. DSM modeling is then applied at ensuing layers enabling a broader, systems-level representation of the interdependencies within the organization system.

\subsection{Uncertainty Recognition}

Two major sources of uncertainty including demand uncertainties and financing uncertainties are considered for the analysis. Similar to many entrepreneurial organizations, demand for Company X's services shapes its strategy, however, there is no absolute forecast model which can accurately predict demand. Demand uncertainties are therefore, a crucial aspect of this analysis. Company $\mathrm{X}$ has also identified the financing of vehicle purchases to be another major source of uncertainty in its decision making process. The purchase of new vehicles would determine the total usage level and hence, the revenue. However, Company X's ability to purchase new vehicles largely depends on its ability to obtain financing from financial institutions, which is beyond their control based on their investor attractiveness when compared with other entities seeking financing. The financing uncertainties therefore come from the fluctuations in the competitors' interest coverage ratio $s c i$ and debt service coverage ratio $d c i$ [Spring 2007].

\subsection{Concept Generation}

\subsection{1 $\quad 1^{\text {st }}$ Layer Analysis}

A high-level or $1^{\text {st }}$ layer DSM model (Figure 2) was developed utilizing the eight domains included in the proposed enterprise architecture (see Table I), and the methods described in Browning [2001] and Eppinger and Browning [2012] to construct a DSM.

The matrix suggests that the domain elements across the top "affect" domain elements down the left column and domain elements in the left column are "dependent" on the domain elements reading across the top. The high coupling between different components in the DSM is especially representative of a start-up environment hence further motivating the need to decompose the system for more detailed analysis.

Figure 3 is used to uncover areas that could be leveraged for flexibility. A ' 0 ' or null means that there is no dependency between the two elements while a ' 1 ' represents a dependency. A weighted scale is sometimes used in considering the relationship between two components, however, in keeping with the goal of simplicity suggested earlier it is felt that such detail does not add significant value in this case. The goal is to identify multipliers and a simple up or down determination was proven to be adequate in making this distinction particularly at the higher layers of the DSM analysis. The CPI was calculated by subtracting the amount of change information $\Delta E_{\text {in }}$ propagating "in" a component by components connected upstream from the amount of change $\Delta E_{\text {out }}$ propagating "out" to other downstream 
components. Once the CPA analysis is completed, focus is placed on the multiplier $(M)$ elements as suggested by Suh et al. [2007], as these elements are deemed to create more uncertainties in the system when subjected to change and are thus, primary candidates for embedding flexibility. The $1^{\text {st }}$ layer CPI analysis highlights those domains that have potential for flexibility, as demonstrated in the next section, for stakeholders who want to be informed but may be faced with time and resource constraints.

\subsection{2 $\quad 2^{\text {nd }}$ Layer Analysis}

Decomposing the domains deemed as "multipliers" into their sub-elements, a more detailed $2^{\text {nd }}$ layer DSM is constructed for better visualization and insights into the system behavior. Only the sub-elements for those domains identified as multipliers in the $1^{\text {st }}$ layer DSM are included in the $2^{\text {nd }}$ layer DSM analysis. The sub-elements included were evaluated in a similar manner as the 1st layer DSM, i.e. taking the sub-element one at a time and asking whether changes to it would affect or be affected by each of the other elements. Non multiplier $1^{\text {st }}$ layer domains are included in the $2^{\text {nd }}$ layer analysis to achieve a holistic analysis of the organization system.

Figure 4 shows the $2^{\text {nd }}$ layer DSM analysis of Company X constructed considering each high level domain. As expected, the $2^{\text {nd }}$ layer analysis provides more specific detail of the inherent dependencies than the high level result did, thus providing more specific focus on where flexibility and real options may be considered. Figure 4 additionally shows the CPA analysis applied to the $2^{\text {nd }}$ layer DSM model. As expected, the sub-elements of each of the high level domains not identified as "multipliers (M)" in the high level analysis were likewise not identified as multipliers here. However, for those high level domains identified as "multipliers", the CPA result clearly shows more specific areas for embedding flexibility. For example, only a subset of the total sub-elements was identified as "multipliers" for both the first layer multiplier domains of "Strategy" and "Stakeholders". Such specification enables strategy generation efforts to focus on just these specific areas.

\subsubsection{Strategy Generation}

The potential areas to embed flexibility can be used to help generate real option strategies, following a process similar to the one proposed by Mikaelian et al. [2011]. Focus is only placed on the multiplier elements identified in the layered analysis. From that perspective, multiple real option strategies can be identified by constantly asking whether such an option would allow some flexibility to be exercised. Using Mikaelian et al.'s [2011] mapping process to consider flexibities both "in" and "on" the enterprise system, Table II shows potential real option strategies and the enablers that can enable such execution. Considering the holistic approach, real option strategies may be enabled by multiple enablers traversing multiple organization domains.

Uncertainty in customer demand creates multiple opportunities for flexibility, depending on whether it is greater or less than expected. For example, as Table II indicates, Company X can increase/decrease its vehicle fleet and parking facilities or implement a number of different pricing strategies to adjust to actual demand dynamics. More specific to MoD companies - and specifically Company $\mathrm{X}$ because of its objective to provide one-way transportation - is vehicle rebalancing. Rebalancing is required to ensure that vehicles are available to meet demand at each of the vehicle share points. Currently, this activity is done manually by having employees redistribute the cars to rental locations, which becomes increasingly costly and difficult to manage as demand for service grows.

As indicated in Table II, Company X has several real option strategies to address the rebalancing requirement. Immediate possibilities include upgrading the operations system to enable more efficiency for the current manual operations or introducing dynamic pricing to encourage the customers themselves to rebalance the vehicles by providing economic incentives. As such, the dynamic pricing option was actually considered in this analysis (see Chapter 4). Multiple organizational domain enablers support each strategy, thus demonstrating the methodology's value in identifying real option strategies that might not otherwise be obvious.

The next section evaluates quantitatively the economic value associated with the real options of limited hardware expansion, used to deal with demand uncertainty, and dynamic pricing to address the rebalancing requirement confronting Company X. This first design reflects flexibility "on" the system. A less obvious option informed by the 
layered analysis, dynamic pricing, provides the ability to "enable time-based fares with a dynamic vehicle or parking space availability-based pricing discount", reflecting flexibility enabled "in" the system.

\subsection{Real Options Analysis}

To date, Company $\mathrm{X}$ has rolled out four car sharing points and two bicycle sharing points. Potential customers first register to Company $\mathrm{X}$, paying a one-off, flat membership fee of $\$ 19$. The price structure for each service is shown in Table III. The following sub-sections profile the flexibility steps described previously to analyze the real options strategies for "expansion flexibility" and "rebalancing flexibility". Both strategies were determined based on the uncertainty drivers affecting Company $\mathrm{X}$ and following the layered process proposed in this paper, in collaboration with Company X. Although more flexibility opportunities exist and can be identified, the following analysis aims to demonstrate how to assess quantitatively the value of such flexibility strategies, to determine whether they are valuable to the company.

\subsubsection{Discounted Cash Flow (DCF) Model}

From a high-level view, Company X's DCF model comprises four basic components that make up any typical DCF model, including revenue $R$, operating costs $C$, net investments $I$ and income tax $T$. The net value in each year $i, V_{i}$ is calculated as follows:

$V_{i}=R_{i}-C_{i}-I_{i}-T_{i}$

The net present value may then be calculated as:

$$
N P V=\sum_{i=0}^{N} \frac{V_{i}}{(1+r)^{i}}
$$

where $r=40 \%$ is the discount rate and $N=20$ is the length of study period. The discount rate was selected based on discussions with Company X's management and consideration of the relatively new and therefore, highly risky market Company $\mathrm{X}$ operates in. The project lifespan was chosen to allow sufficient time for the system to grow and reach a reasonably stable state.

Table IV presents all the parameters used in the economic model. Table V indicates the DCF components and the formulae used to calculate their value. However, component growth can, in fact, be modeled around the following key parameters.

\subsubsection{Market demand}

The market demand for Company X's services may be viewed from a Product Life Cycle perspective as introduced by Dean [1950]. The growth in the number of members is modeled based on a S-shape curve, where $M$ is the market demand, $R$ is the upper bound on the number of members, $\alpha$ is the translation parameter and $\beta$ is the sharpness parameter. At the same time, vehicle utilization, captured by the yearly number of bookings per vehicle, $B$, will also grow as the membership pool grows similarly following an S-shaped curve. Thus, the number of members $M_{i}$, and similarly $B$, follows:

$$
M_{i}=\frac{R}{1+\alpha e^{-\beta i}}
$$

Table VI shows the market demand estimated for the city of interest, based on conversation with Company $\mathrm{X}$ representatives. $R$ is estimated using benchmarking data from organizations similar to Company $\mathrm{X}$ and local demographics while $\alpha$ is estimated by 


$$
\alpha=\frac{R}{M_{1}}-1
$$

for $M_{i}$ and similarly for $B_{i 1}$ and $B_{i 2}$. The sharpness parameter reflects that the growth rate is highest for $M_{i}$ as membership may grow without actually resulting in vehicle bookings. Both $M$ and $B$ determine the revenues collected from membership fees and usage charges. In the DCF model, the number of bookings per vehicle is further broken down based on the type of service. In addition, the model accounts for the fact that both the electric car and shuttle services share the same vehicle fleet.

\subsubsection{Number of sharing points}

The number of sharing points $P_{i j}$ built each year is assumed to grow independently over the system lifecycle, as it is subjected to investor funding and government approval. It is also assumed to take on an S-shaped distribution as shown in Table VII.

\subsubsection{Vehicle fleet size}

The number of new cars purchased each year, $V_{p}$, is based on the number of members enrolled. Millard-Ball [2005] reports an optimum car-to-member sharing scheme ratio of 1:27. It is assumed here that Company $\mathrm{X}$ will strive towards this ratio by the end of year 20. The vehicle-to-member ratio, $\theta$, is therefore introduced and $V_{p}$ in year $i$ is $\theta_{i}$ multiplied by $M_{i}$ unless $V_{p}$ exceeds the total capacity of the sharing points. Assuming the current value for the car-to-member ratio $\theta_{c l}$ is 0.05 and $\theta_{c 20} \approx 0.03, \theta_{c i}$ can therefore be assumed to follow a straight line represented by the linear equation $\theta_{c i}=0.00132 * M i+0.00368$. Meanwhile, the current bicycle-to-member ratio $\theta_{b i}$ is assumed to be sufficient based on a comparison with that of similar MoD operator Velib in its first few years [NYC Department f City Planning, 2009]. Company X's current $\theta_{b i}$ is, therefore, maintained throughout the length of study.

\subsubsection{Financing opportunities}

Company X plans to finance the purchase of new cars with bank loans. They may, however, have to lease cars from external vendors to meet $V_{p}$ if they are unable to obtain loans. To determine if loans would be allocated to Company $\mathrm{X}$, its interest coverage ratio sci and debt service coverage ratio $d c i$ are computed and benchmarked against the common acceptable ratios. To successfully secure loans both $s c i$ and $d c i$ have to be positive and greater than those belonging to other organizations competing for the loans. If loans are obtained $V_{c}=V_{p}-V_{\mathrm{a}}$, where $V_{\mathrm{a}}$ is the actual vehicle fleet size. If unsuccessful, $V_{c}=0$ requiring Company $\mathrm{X}$ to lease cars to maintain the targeted vehicle-to-member ratio. The cost of financing is assumed to include $10 \%$ down payment, $90 \%$ principal payment and 5 -year interests at $3.25 \%$.

\subsubsection{Manpower size}

Several parameters are introduced to model vehicle rebalancing, namely the average daily number of vehicles which need rebalancing $V_{r}$, the ideal number of employees needed to rebalance $E_{d}$ and the actual number of employees to rebalance $E_{b}$. Currently, Company X indicates that it takes one employee to rebalance 3 vehicles hence, $E_{d}=V_{r} / 3$. The daily number of vehicles that need rebalancing is shown as an average but is actually highly unpredictable and fluctuates daily. As such, Company $\mathrm{X}$ would not be able to hire the ideal number of employees needed to rebalance and therefore, would hire $E_{b i}=E_{d(i-l)}$ employees in year $i$. In addition to the number of employees hired to rebalance vehicles, staff working in the office is also included in the head count at Company X.

\subsubsection{Number of vehicles for use}

Usage charges collected depend on the yearly number of bookings made, which depends on the average number of vehicles available for use. This parameter is greatly affected by the ability of Company $\mathrm{X}$ to rebalance vehicles effectively. Unavailable and idle vehicles will not generate any revenue. Therefore, the number of vehicles available for use is equal to $V_{a}-V_{b}+3 E_{b}$. 


\subsubsection{Uncertainty Analysis}

Building on the deterministic model, uncertainties affecting Company X are incorporated in the DCF model. As previously discussed, in the case of Company $\mathrm{X}$, demand uncertainty and financing uncertainty are considered here.

\subsubsection{Demand uncertainties}

Thavikulwat [1989] models demand uncertainties using fluctuations around center points determined by S-shaped curves. The fluctuation is modeled with normal distributions taking the center point determined by S-curves as the mean $\mu$. The standard deviation $\sigma$ is $\tau \mu$ where $\tau$ is a fixed percentage of the mean, deemed as $50 \%$ to simulate sufficiently high fluctuation from the forecast.

In addition, random variation is embedded into the $\mathrm{S}$-curve parameter to account for forecast errors as described in Table VIII. The amount of errors also reflects the extent of uncertainty on each parameter. For instance, as the initial values for $P_{i 1}$ and $P_{i 2}$ are known, no fluctuation is embedded. Random uniform distribution is embedded into the percentage of cars used for the shuttle service and the average daily number of vehicles to be rebalanced $V_{\text {rij. }}$. Estimation for the distribution parameters used is then made based on observations. For instance, in the best case scenario, there are no vehicles to be rebalanced at any point in time while in the worst case scenario, all vehicles have to be rebalanced. Hence, the average daily number of vehicles to be rebalanced may be assumed to follow $U\left(0, F_{i}\right)$ where $\mathrm{F}_{\mathrm{i}}$ is the actual fleet size in year $i$.

Figure 5 illustrates how demand fluctuates under uncertainty. As shown, different S-curves are generated for $M_{i}$ in each simulation run.

\subsubsection{Financing uncertainties}

Company X's ability to purchase new vehicles largely depends on their ability to obtain financing. The uncertainties therefore, come from the fluctuations in the competitors' interest coverage ratio sci and debt service coverage ratio $d c i$ [Spring 2007]. To embed these uncertainties into the DCF model, the competitor's interest coverage ratio is assumed to take on a uniform distribution between 2.5 and 3.5 each year while the debt service coverage ratio takes on a uniform distribution between 1.15 and 1.35. The values of these parameters are chosen based on the typical minimum ratios required by most commercial banks [Marks et al. 1982].

\subsubsection{Flexibility Analysis}

Two flexible designs were chosen for the real options analysis. The first design, which deals with strategy and infrastructure, explores the ability to halt the expansion of electric car services temporarily when demand is lower than desired. The second design explores a dynamic pricing technology to aid vehicle rebalancing in Company X's system, thus dealing with strategy, stakeholders and technology elements from the DSM analysis. The former is simply the option to defer investments when demand is lower than expected which is a typical strategy that can be implemented on any system. The latter, however, is unique to a mobility-on-demand transportation system.

\subsubsection{Flexibility expansion}

The electric car and shuttle services face larger operating costs due to much higher costs for leasing, electricity, maintenance and site rental. As a result, its operating profit is more volatile, resulting in a greater possibility of running into losses. In this design, the decision rule is to suspend the expansion of electric car sharing points and car fleet size by maintaining the same number of sharing points and fleet size if the operating profit, $\mathrm{O}$, for car service for the previous year is negative or has been declining for the preceding two years. In the DCF model, this is captured by setting: 


$$
\begin{gathered}
\text { If }\left(O_{i-1}<0 \text { OR } O_{i-1}-O_{i-2}<0\right) \text { Then } \\
P_{i 1}=P_{i-1} \\
V_{a i l}=V_{a(i-1) 1}
\end{gathered}
$$

\subsubsection{Flexibility rebalancing}

Currently it takes one employee to rebalance every three vehicles. As the number of vehicles varies greatly from year to year, there is great difficulty in predicting the number of employees to be hired each year. One vehicle rebalancing solution that may ease this burden is achieved through a dynamic pricing strategy. Each car is fitted with a monitor, which shows alternative sharing points around the customer's destination. Customers would then be given incentives, whether through discounted fare or reward point accumulation, to return vehicles to sharing points with an imbalanced number of cars. The incentives are higher based on the number of cars a sharing point needs. Therefore, pricing is not fixed, but rather dynamic depending on the number of cars parked at each sharing point at any time of the day. In the base case scenario, it is assumed that the average number of cars to be rebalanced each year follows a uniform random distribution. With dynamic pricing applied the average number of cars to be rebalanced each year may be assumed to take on lower values with greater probability. $V_{r i j}$ is, therefore, assumed to follow an approximately triangular distribution with 0 for the lower limit and the actual car fleet size as the upper limit as Figure 6 shows.

Under this distribution, there is a greater likelihood to have fewer cars to be rebalanced. This would result in a smaller, more stable manpower size and thus, lower manpower costs. However, a loss of revenue resulting from the incentives given to customers, which takes an assumed value $\gamma$ of $1 \%$ of car usage charges is also incurred.

\subsubsection{Combined designs}

The analysis is also extended to the case where both expansion flexibility and rebalancing flexibility are combined. In this case, the DCF model is modified to integrate additional parameters, as well as the adjusted probability distribution simultaneously.

\section{RESULTS AND DISCUSSION}

This section presents the simulation results and discusses the validity and limitations of our method. Figure 7 shows the cumulative probability distribution (CDF) curves for the different designs as obtained through a Monte Carlo simulation over 2,000 runs. Each curve illustrates the probability of achieving a particular NPV or lower for a specific design. Table IX summarizes the values for each performance metric across the different designs.

As shown in Figure 7 and Table IX, the ENPV (or mean NPV) for flexible expansion is slightly better than the base case, but significantly greater for flexible rebalancing and the combined design. These results imply that these design and management strategies are of value to Company X's mobility-on-demand transportation system. They show that a system deployed without flexibility or only flexible expansion could lead to potential losses, and be a showstopper for most companies. Considering flexibility, however, adds a significant amount of value, reversing the recommendation to go ahead with the venture as a value-creating project.

While only slightly, the CDF curve for flexible expansion mostly lies to the right of that of the base case - indicating near stochastic dominance. This suggests some opportunity to defer expansion which reduces the risk of running into losses during consecutive years of low demand, thus decreasing exposure to downsides. Furthermore, it enables Company $\mathrm{X}$ to grow sufficient reserve, resulting in better interest and debt service coverage ratios to finance its vehicle purchase when demand is high.

Meanwhile, the CDF curves for both flexible rebalancing and combined designs are completely to the right of that of the base case, suggesting that these cases are capable of both increasing upside opportunities and reducing exposure to downside conditions. When the demand for Company X's vehicles is high, flexible rebalancing ensures that there are sufficient vehicles at the right place and at the right time to capture this demand. Taking into account that vehicle costs are largely incurred regardless of the demand level, this design reaps greater earnings per vehicle compared to 
the base case where demand might not be fully captured. This results in a more desirable interest coverage ratio and debt service coverage ratio in general, reducing the risk of having lower ratios than the competitors and thus, increasing the ability to obtain financing. The combined design allows Company $\mathrm{X}$ to capitalize on the benefits offered by both flexible expansion and flexible rebalancing. However, the CDF curve for the combined design is not the right most curve. This is expected as the increased upside from flexible rebalancing has to make up for the slightly decreased upside of flexible expansion.

It is worth noting that the variability of all the recommended designs, reflected by the standard deviations in Table IX, is comparable or even better than that of the base case. Thus flexibility not only helps generate more value, it also helps better mitigate some of the risks inherent to such an entrepreneurial venture.

Flexible rebalancing is the best strategy based on six performance metrics, including the ENPV, minimum NPV, value at risk, value at gain, standard deviation (as proxy for risk), and value of flexibility although it incurs the greatest additional CAPEX due to the cost of upgrading the vehicle fleet to enable dynamic pricing capability. The value of flexibility is the upper bound that one would be willing to pay to enable it in the system. If the additional CAPEX is deemed more than the flexibility is worth then flexible expansion should be the design of choice. Finally, the combined design is not recommended, as the ENPV is lower than that of flexible rebalancing despite having to commit the same level of CAPEX.

\subsection{Sensitivity Analysis}

\subsubsection{Sensitivity to Changes in Flexible Expansion Decision Rule}

In Figure 8, the number of consecutive years of losses needed before Company $\mathrm{X}$ decides to halt the expansion of its electric car service is varied. The results show that all designs are insensitive to this change in the decision rule. The same can be said about the variation in the number of consecutive years of decreasing operational profit needed before Company X stops expanding the car services, as shown in Figure 9 (i.e. not much change is observed).

\subsubsection{Sensitivity to Changes in Flexible Rebalancing Decision Rule}

In Figure 10 the amount of incentives given to customers in the dynamic pricing scheme is varied. The expected NPV decreases with increasing losses as anticipated. The indifference point is around 0.4 and thus, this design is more valuable than the base case only if Company $\mathrm{X}$ does not lose more than $40 \%$ of its car revenues as a result of implementing this scheme.

\subsection{Validity, Limitations, and Future Work}

Applying the process proposed to the realities of Company $\mathrm{X}$ has demonstrated quantitatively that the flexible designs elicited systematically from the proposed process are indeed valuable to an organization system supplying mobility on demand services in terms of dealing with demand and financing uncertainties. The real options analyses performed concludes that the flexible rebalancing design is of higher value than the flexible expansion and combined designs as long as Company $\mathrm{X}$ is willing to invest in the additional capital expenditure and no more than $40 \%$ of revenue is lost to incentives.

\subsubsection{Internal validity}

Scrupulous effort was made throughout the study to ensure data representativeness from meetings and discussions with Company X stakeholders, and benchmarking with similar organizations in the MoD transportation sector. The choice of domains specific to Company X and the DSM iterations conducted were presented to key stakeholders to ensure that they closely reflected reality. Regarding the real options analysis itself, internal validity of the results was ensured via discussions with key stakeholders to capture the system characteristics accurately, such as the types of uncertainties faced and the appropriate discount rate, to avoid biased preconceptions on how the system should behave. The designs were then tested for robustness using one-way sensitivity analysis to anticipate possible inaccuracy in parameter estimation and other errors, as discussed in the previous section.

While care was taken to utilize the most accurate data by involving key stakeholders and conducting relevant benchmarking, the analysis itself was, in fact, conducted by non-members of the organization. As such, knowledge of the day to day activity and thus the specific interdependencies of the organization domains and sub elements when 
constructing the DSM models and the assumptions used in the real options analysis is speculative in some instances. It is felt that the involvement of actual key stakeholders in physically applying the process could minimize any inaccuracies in the analysis and thus add further validity to the process being proposed.

Therefore, to further strengthen the validity, future case studies should incorporate direct key stakeholders involvement in applying the methodology such as, physically developing DSM models and conducting the real option analysis to ensure that the most accurate data is being considered. For example, direct involvement of key stakeholders would certainly enable the creation of DSM models with the most accurate cause-to-effect relationships.

\subsubsection{External validity}

Applying the proposed process to Company $\mathrm{X}$ validates its value particularly for organizations operating in the MoD sector. Regarding the process itself, interviews were conducted with three researchers conducting future mobility research at the National University of Singapore to compare the proposed process with that of an alternative process proposed and tested by Cardin et al. [2013]. All three of the interviewees were obviously familiar with MoD transportation systems, but only one was actually familiar with Company X. During the interview each was asked the following prompting questions, one at a time, after being given a description of Company $\mathrm{X}$ and their inherent objectives as an organization:

1) What are the major sources of uncertainty affecting the future performance of this system?

2) What flexible strategies would enable the system to change and adapt if the uncertainty scenarios you just discussed occur during operations?

3) How should you prepare, engineer and design this particular system to enable the flexibilities you just discussed?

4) How should you manage and decide when it is appropriate to use or exercise the flexibilities in this system?

In regards to question one, all three respondents answered by suggesting demand but only one speculated beyond demand to include other uncertainties such as financing. Regarding question two, two of the respondents offered the concept of having to make cars available where they were needed. One explicitly stated "having to move cars around" while the other suggested the need to move vehicle share points. However, when asked question three and four very little specifics were expressed and neither of the two respondents suggested any flexibility strategies for dealing with the issue of making cars available. When shown the process being proposed here all three interviewees responded favorably suggesting that the process was interesting and useful in enabling the identification of flexibility strategies. The interviewee familiar with Company $\mathrm{X}$ acknowledged the inclusion of some strategies that she would not have thought of otherwise. While this exercise is not conclusive in that the interviewees did not actually use the process to identify the strategies themselves it is felt that given their expertise in the MoD field it does demonstrate the value the process has in enabling the thought process for embedded stakeholders in identifying flexibility opportunities in the systems they are designing.

Based on the results, one can certainly argue that the process can be applied to other MoD transportation systems as demand and financing uncertainties are arguably similar in these environments. In addition, it is believed that the process proposed can also be generalized to other systems that are similar in characteristic, i.e. large, complex, long lifecycle and/or facing much uncertainty. For example, organizations that participate in industries with major disruption could use this methodology to define a strategy for navigating and managing such disruption. Consider the U.S. telecom and manufacturing industries. The former has undergone a complete transition from traditional landline technology dominance to VOIP and wireless technology while the latter has seen a mass exodus of manufacturing jobs to overseas destinations. Additionally, metropolitan systems, such as Singapore, which has seen rapid growth, could also benefit from the process proposed here. All exemplify the characteristics cited above with a hybrid myriad of physical and social components. A process that enables a dynamic analysis of the interrelationships of the multiple components and the emergence of real option opportunities to embed flexibility for the best strategic result could enable such organizations or those managing such systems from the pit falls of mistakes. In the case of telecom and manufacturing companies better managing the very disruption of their industries and in the case of large cities, the process could help manage the resulting expansion needs from rapid population growth. 
However, this study is one test case in one industry sector. Applying the process to different business sectors or simply other large complex systems where the system characteristics or values for sensitive parameters vary may lead to a different conclusion altogether unless suitable modifications are made. Further application is therefore necessary to verify the methodologies dependability and applicability to such examples as those suggested above.

\subsubsection{DSM modeling}

Another limitation in this study is related to constructing the detailed DSM. While there is no limit to the size of a DSM, the number of elements certainly has to be kept manageable in order to be practical for industrial use. Browning [2001] stated that DSMs with more than ten elements may best be built by integrating smaller DSMs. Indeed, the building of the detailed $2^{\text {nd }}$ layer and subsequent layer DSM's can be challenging. In addition, the DSM constructed here does not factor in the degree of dependency between two elements. It follows the conventional binary representation, i.e. ' 0 ' (or null) and ' 1 ', to show the existence of a dependency without offering further information on the nature of the interaction. While such detail was deemed unnecessary in this application it is still suggested as a consideration for future work, particularly for DSM construction subsequent to the highest layers. Thus, future work will involve experimenting with various DSM modeling methods to address these issues. One example is to construct smaller DSMs first and then integrating them later. Another example would be to extend the configuration of the DSM by replacing the binary numbers with probability numbers or even with a scale to signify the strength of the dependency, as done by $\mathrm{Hu}$ and Cardin [2015]. Further consideration of even lower layer domain views of the organization and/or proposing a more specific question and defining more specific sub-elements based on the expertise of key stakeholders will also be considered to enable more defined relationships between the different components. In addition, deeper exploration into each multiplier domain by building a separate detailed DSM for each would enable the study of the interactions of its inherent sub-elements which could potentially present new interesting findings.

\subsubsection{Real option analysis}

The real option analysis is not flawless as there are underlying assumptions that cannot be validated unless further studies are conducted. For example, the assumption that the average number of vehicles to be rebalanced takes on uniform random distribution in the base case scenario and triangular distribution in the flexible rebalancing design could be adjusted. Therefore, further studies focused on assessing the impact of different probability distributions could be done. Market studies or discrete-event simulations to examine if users would indeed be encouraged to help rebalance vehicles, if given the incentives proposed, could also be done. Other studies may include demand modeling for MoD transportation systems in Singapore and flexibility analysis for a more mature mobility-on-demand transportation system. Finally, building simulation models to simulate the current operating system of Company X and a hypothetical system that considers real options embedded into the model could be considered. For example, the model could consider fluctuating the demand distribution and/or varying the number and types of employees among other key characteristic changes to observe how such changes affect other key variables in the model such as the optimum fleet size to have on a particular site, the service level provided during a particular time period and the distribution of fleets around Singapore, etc. Such modeling would need to consider not only the MoD transportation system in question, but also other complex systems that it may affect or be affected by.

\subsection{Developments for Process Management}

Cardin [2014] distinguished between the process management phase, in the flexibility design framework, and the previous four phases by suggesting that "it addresses the social and collaborative setting under which flexibility is generated". Acknowledging the difficulty in managing the design process for flexibility due to a "silo" culture prevalent in many organizations, the process management phase is designed to reduce barriers to implementation and stimulate creativity by introducing methodologies that help stakeholders actually execute flexible design concepts when the timing is ripe for implementation. As such, methodologies that consider the social interactions of multiple stakeholders are touted as a means of ensuring that once flexible strategies have been incorporated into the system design they are, in fact, ultimately implemented should it be deemed desirable to do so. The process proposed here, with its specific focus on the concept generation phase, is not designed to address this particular issue confronting the successful implementation of flexibility in complex system design. Instead, it is designed, more specifically, as a way 
for stakeholders either individually or in collaboration with other stakeholders to consider and identify opportunities where flexibility can be considered. In discussing the "Shell Approach to Planning", Beck [Beck, 1982] suggests that planning starts with an acceptance of uncertainty and suggests that Shell planners try to identify the key elements pertaining to a particular area of decision making and translate them into a framework for individual judgment. The process proposed here is a tool enabling key stakeholders to consider the uncertainty the organization is confronted with, and identify potential real option strategies from a holistic perspective that enhances strategic decision making and when exercised contributes to continued and greater life cycle success. However, ensuring that the flexibility that has been embedded into the system design is actually executed is beyond the scope of the process being proposed here.

\section{CONCLUSION}

Academic research has recognized, through descriptive writings and the proposal of tools and methodologies, the importance of both DSM modeling and flexibility analysis in the system design and implementation process of complex systems. Much of the previous work has been exclusive to one or the other and mostly focused on physical and mature products. In this paper we present the findings of work being conducted that embraces both to assess an entrepreneurial organization called to become a complex system, and aiming at improved strategic design and management decision-making for better lifecycle performance. By applying the proposed process to MoD operator Company $\mathrm{X}$, a systematic approach capturing gradually complex systems-level information of an organization system was demonstrated. The layered DSM process demonstrated that the systematic framework and techniques integrated in it can guide practitioners to model their system and identify components that require more flexibility.

Understanding the interdependencies of the organizational system and identifying and implementing flexibility is essential to improving the lifecycle performance of entrepreneurial organizations which are particularly vulnerable to uncertainty. While the process is somewhat limited by its focus on aleatoric uncertainty, evaluation results performed for two of the real options identified from the process showed a positive outlook, suggesting that the adoption of such a method would bring about value to a company in the long run. In this instance, verification that flexible design elicited systematically from a layered analysis is indeed valuable to Company X's mobility-on-demand transportation system in terms of dealing with demand and financing uncertainties was quantitatively demonstrated. Specifically, while both real options demonstrated results in a value position, the real options analyses performed concludes that the flexible rebalancing design is of higher value than the flexible expansion and combined designs as long as Company $\mathrm{X}$ is willing to invest in the additional capital expenditure and no more than $40 \%$ of revenue is lost to incentives. While applying the process to Company $\mathrm{X}$, with arguably definable uncertainties, may initially minimize consideration of epistemic uncertainty, the analytical results nonetheless demonstrate that it can help start-up companies like Company X make strategic decisions based on defined models.

The conclusions of this work are anticipated to contribute to the existing body of knowledge on DSM. Specifically, the introduction of the layered DSM and the conclusion that DSM modeling can be used to offer a broader, systemslevel representation and description of entrepreneurial organizations. In addition, this work contributes to industry practice in terms of offering a process to identify potential components in the organizational system to embed flexibility as the system evolves, with an eye towards improving lifecycle performance. This approach will help entrepreneurial companies confront uncertainty and embrace resulting changes to minimize detrimental effect and maximize value to the growing organization as more information is available. This analysis supports strategic decision-making with a quantitative economic assessment that can be compared to the cost of enabling flexibility. In this case, only the strategies offering higher expected economic value, as compared to the cost of acquiring the flexibility (e.g. implementing a dynamic pricing strategy in the case of Company X), should be pursued by the startup organization.

\section{ACKNOWLEDGMENT}

We are thankful for the insightful comments provided by Amedeo Odoni. This work was funded by the SingaporeMIT Alliance for Research and Technology via sub-awards 25 and 37, and administered via WBS R-266-000-069592 and R-266-000-076-592. 


\section{REFERENCES}

P. W. Beck, Corporate planning for an uncertain future, Long Range Planning, vol. 15, no. 4, 1982, pp. 12-21.

M. Brown, Electronic bike running cost: What are the running cost of owning an electric bike?, e-bikeshop.co.uk blog, 2013 Website: https://www.e-bikeshop.co.uk/blog/post/electric-bike-running-costs/

T. R. Browning, Applying the design structure matrix to system decomposition and integration problems: A review and new directions, Engineering Management, IEEE Transactions, vol. 48, no. 3, 2001, pp. 292-306.

L.W. Businetz and J.B. Barney, Differences between entrepreneurs and managers in large organizations: Biases and Heuristics in Strategic Decision-Making, Journal of Business Venturing, vol. 12, 1997, pp. 9-30.

M.-A. Cardin and R. de Neufville and D. M. Geltner, Design catalogues: A practical approach to design and value flexibility in engineering systems, Systems Engineering (Accepted), 2015.

M.-A. Cardin, G. L. Kolfschoten, D. D. Frey, R. de Neufville, O. L. de Weck and D. M. Geltner, Empirical evaluation of procedures to generate flexibility in engineering systems and improve lifecycle performance, Research in Engineering Design, vol. 24, no. 3, 2013, pp. 277-295.

M.-A. Cardin, Enabling flexibility in engineering systems: A taxonomy of procedures and a design framework, Journal of Mechanical Design, vol. 136, no. 1, 2014.

M. Danilovic and T. R. Browning, Managing complex product development projects with design structure matrices and domain mapping matrices, International Journal of Project Management vol. 25, no. 3, 2007, pp. 300-314.

J. Dean, "Pricing Policies for New Products", Harvard Business Review, vol. 28 (November-December), 1950 , pp. 45-53.

R. de Neufville and S. Scholtes, Flexibility in engineering design, MIT Press, Cambridge, MA, 2011.

O. L. de Weck, C. Eckert and J. Clarkson, A classification of uncertainty for early product and system design, Proceedings of ICED, Citeseer, 2007.

O. L. de Weck, R. de Neufville and M. Chaize, Staged deployment of communications satellite constellations in low earth orbit, Journal of Aerospace Computing, Information, and Communication, vol. 1, 2004, pp. 119-136.

C. Eckert, P. J. Clarkson and W. Zanker, Change and customisation in complex engineering domains, Research in Engineering Design, vol. 15, no. 1, 2004, pp. 1-21.

S. D. Eppinger and T. R. Browning, Design structure matrix methods and applications, MIT Press, Cambridge, MA, 2012.

M. J. Foster, Scenario planning for small businesses, Long Range Planning, vol. 26, no. 1, 1993, pp. $123-129$.

N. Khatri and H.A. Ng, The role of intuition in strategic decision making, Human Relations, vol. 53, no. 1, 2000 , pp. 57-86.

G. Iaccarino, "Introduction to Uncertainty Quantification”, Mechanical Engineering \& Institute for Computational Mathematical Engineering, Stanford University, 2011.

A. D. Kiureghian and O. Ditlevsen, “Aleatory or epistemic? Does it matter?”, Special Workshop on Risk Acceptance and Risk Communication, Stanford University, 2007.

E. C. Koh, N. H. Caldwell and P. J. Clarkson, A technique to assess the changeability of complex engineering systems, Journal of Engineering Design, vol. 24, no. 7, 2013, pp. 477-498.

H. Lewis, N. Allan, C. Ellinas and P. Godfrey, Engaging with risk, CIRIA, London, UK, 2014.

C. H. Loch, M. E. Solt and E. M. Bailey, Diagnosing unforeseeable uncertainty in a new venture*, Journal of product innovation management, vol. 25, no. 1, 2008, pp. 28-46.

A. MacCormack and K. Herman, The rise and fall of iridium, Harvard Business School Case, 2001, pp. 9-601.

K. Marks, L. Robbins, G. Fernandez, J. Funkhouser, and D. Williams, The handbook of Financing Growth, John

Wiley \& Sons, Hoboken, NJ, United States, 2009.[28] P. W. Beck, "Corporate planning for an uncertain future," Long Range Planning, vol. 15, 1982, pp. 12-21.

T. Mikaelian, D. J. Nightingale, D. H. Rhodes and D. E. Hastings, Real options in enterprise architecture: A holistic mapping of mechanisms and types for uncertainty management, Engineering Management, IEEE Transactions on, vol. 58, no. 3, 2011, pp. 457-470.

A. Millard-Ball, "Carsharing: Where and How It Succeeds." In TCRP Report 108: Transportation Research Board of the National Academies. Washington, D.C., 2005.

NYC Department of City Planning, Bike-Share opportunities in New York City, Spring 2009.

Project Management Institute, A Guide to the project management Body of Knowledge (PMBOK) - Fifth Edition, Project Management Institute, Inc., Newton Square, PA, United States, 2013.

D. H. Rhodes, A. M. Ross and D. J. Nightingale, Architecting the system of systems enterprise: Enabling constructs and methods from the field of engineering systems, Systems Conference, 2009 3rd Annual IEEE, IEEE, 2009, pp. 190-195. 
N. Rojagopalan, A. M. A. Rasheed and D. K. Datta, Strategic decision processes: critical review and future directions, Journal of Management, vol. 19, no. 2, 1993, pp. 349-384.

SPRING Singapore. Financial Handbook for SMEs. Retrieved from SPRING Website: http://www.spring.gov.sg/Resources/Documents/Guidebook_Financial_Handbook_for_SMEs.pdf, 2007.

E. S. Suh, O. L. De Weck and D. Chang, Flexible product platforms: Framework and case study, Research in Engineering Design, vol. 18, no. 2, 2007, pp. 67-89.

P. Thavikulwat, "Modeling the human component of computerized business simulation", In T. Pray \& J. Wingender (eds.), Developments in business simulations and experimental exercises, Oklahoma State University, Stillwater, OK, United States, 1989, pp. 37-40.

L. Trigeorgis, Real options: Managerial flexibility and strategy in resource allocation, MIT Press, Cambridge, MA, United States, 1996.

T. Wang and R. de Neufville, Building real options into physical systems with stochastic mixed-integer programming, Eighth Real Options Annual International Conference, Montreal, Canada, Citeseer, 2004. 
Table I. COMPANY X ORGANIZATIONAL FRAMEWORK AND SYSTEMS LEVEL

\begin{tabular}{|l|l|}
\hline \multicolumn{1}{|c|}{ Domain } & \multicolumn{1}{c|}{ Description } \\
\hline Service & $\begin{array}{l}\text { The product offered by the organization. For Company X this includes electric bike and car } \\
\text { rental services and a chauffeured shuttle service. }\end{array}$ \\
\hline Strategy & $\begin{array}{l}\text { The vision and business model by which the organization will provide the services offered and } \\
\text { expand its business. For example, the mix of services offered and related pricing are key } \\
\text { strategy components. }\end{array}$ \\
\hline Organization & $\begin{array}{l}\text { The structure of the organization managing the day-to-day business needs. Typical of most } \\
\text { early stage start-ups, Company X's structure is not clearly defined but expected to become more } \\
\text { focused as the organization grows. }\end{array}$ \\
\hline Infrastructure & $\begin{array}{l}\text { The physical assets of the organization. For Company X this includes electric bikes and } \\
\text { automobiles, parking facilities and the operations support system. }\end{array}$ \\
\hline Stakeholders & $\begin{array}{l}\text { The human element of the organization. For Company X this includes the current work force, } \\
\text { customers, investors and other groups with vested interest in the types of services being offered } \\
\text { by Company X. }\end{array}$ \\
\hline Operations & $\begin{array}{l}\text { The day-to-day activities required to provide the product being offered. For Company X this } \\
\text { includes but is not limited to fleet maintenance, fleet rebalancing and registration/reservation } \\
\text { support. }\end{array}$ \\
\hline Technology & $\begin{array}{l}\text { The technology utilized by the organization to provide the offered product. For Company X } \\
\text { this includes fleet (self-piloted cars) and operations improvement. }\end{array}$ \\
\hline
\end{tabular}

Table II. REAL OPTION POSSIBILITIES

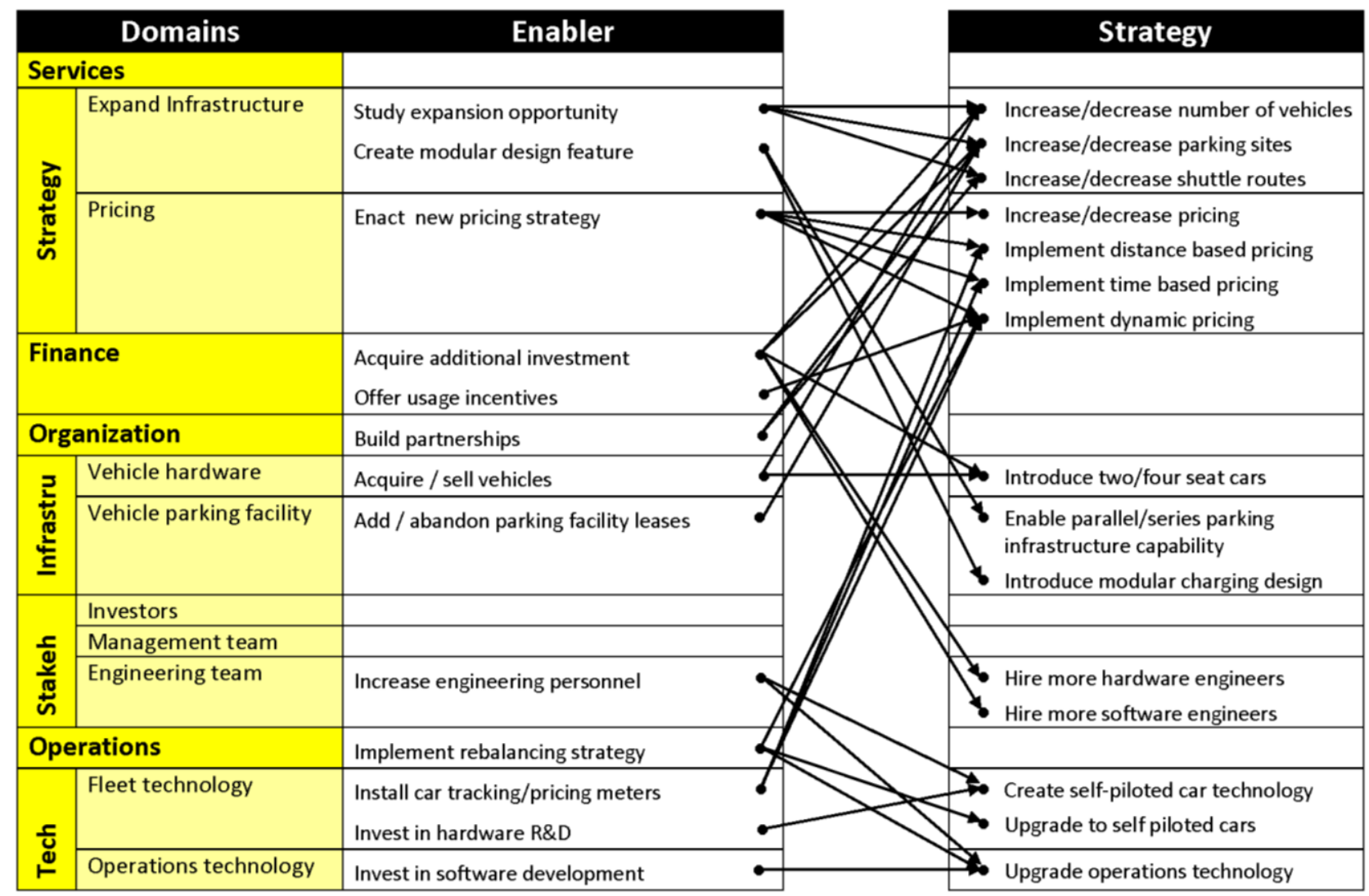


Table III. COMPANY X PRICE STRUCTURE

\begin{tabular}{|c|c|c|c|}
\hline & Car & Bicycle & Shuttle \\
\hline Usage Charge & $\begin{array}{l}\$ 0.39 / \mathrm{min} \text { (driving) } \\
\$ 0.19 / \mathrm{min} \text { (parking) }\end{array}$ & \$0.10/min & $\$ 3+\$ 0.39 / \mathrm{min}$ \\
\hline 24-hour cap & $\$ 75$ & $\$ 15$ & N.A. \\
\hline Insurance & \multicolumn{3}{|c|}{ Included } \\
\hline Distance & \multicolumn{3}{|c|}{ Unlimited } \\
\hline Electricity & \multicolumn{3}{|c|}{ Included } \\
\hline
\end{tabular}

\begin{tabular}{|c|c|c|c|}
\hline & Car & Bicycle & Shuttle \\
\hline Usage Charge & $\begin{array}{l}\$ 0.39 / \mathrm{min} \text { (driving) } \\
\$ 0.19 / \mathrm{min} \text { (parking) }\end{array}$ & $\$ 0.10 / \mathrm{min}$ & $\$ 3+\$ 0.39 / \mathrm{min}$ \\
\hline 24-hour cap & $\$ 75$ & $\$ 15$ & N.A. \\
\hline Insurance & \multicolumn{3}{|c|}{ Included } \\
\hline Distance & \multicolumn{3}{|c|}{ Unlimited } \\
\hline Electricity & \multicolumn{3}{|c|}{ Included } \\
\hline
\end{tabular}


Table IV. MODEL PARAMETERS 


\begin{tabular}{|c|c|c|}
\hline Symbol & Parameter & Estimation \\
\hline$V_{i}$ & Net value & \\
\hline $\boldsymbol{R}_{i}$ & Revenue & \\
\hline$C_{i}$ & Operating cost & \\
\hline$I_{i}$ & Net investments & \\
\hline$T_{i}$ & Income tax & Based on current singapore rates \\
\hline$M_{i}$ & Number of members in year $i$ & $\begin{array}{l}\text { Initial number of registrants of } 1,029 \text { based on current member total. The maximum registrants } \\
\text { estimated using } 1 \% \text { of total number of car owners in Singapore. }\end{array}$ \\
\hline$R$ & Upper bound on the number of members & \\
\hline$\alpha$ & Translate parameter & \\
\hline$\beta$ & Sharpness parameter & \\
\hline$B_{i j}$ & $\begin{array}{l}\text { Number of bookings per vehicle for } \\
\text { service, } j-1,2 \text { (car and bicycle) }\end{array}$ & $\begin{array}{l}\text { Based on City CarShare (San Francisco) average yearly bookings (790) per vehicle in its first five } \\
\text { years. Maximum number of bookings assumes } 3 \text { bookings per } 12 \text { hours of operation. Bicycle yearly } \\
\text { bookings (1,310) based on Velib (Paris) first year operation. Maximum bookings assumes } 16 \text { total } \\
\text { bookings per } 12 \text { hour span. }\end{array}$ \\
\hline$S_{i}$ & Number of bookings for shuttle service & $\begin{array}{l}\text { Assumed that out of the Singapore average total monthly taxi rides of } 21 \text { million, Company } X \text { would } \\
\text { share the equivalent of the proportion of its car fleet size to the total fleet size owned by all taxi } \\
\text { companies in Singapore which is } 27,703 \text {. }\end{array}$ \\
\hline Duj & $\begin{array}{l}\text { Average duration of use in minutes for } \\
\mathrm{j}=1,2,3 \text { (car, bicycle, shuttle) }\end{array}$ & $\begin{array}{l}\text { Based on City CarShare case study, out of } 3 \text { hours and } 45 \text { minutes average booking duration, } \\
\text { customers generally drive for } 20 \text { miles. Assuming average car speed of } 25 \mathrm{mph} \text {, the average duration } \\
\text { of driving per booking is } 48 \text { minutes. For bikes assumes average ride duration of } 25 \% \text { of maximum } \\
\text { battery distance. Shuttle is based on average taxi ride duration of } 22 \text { minutes. }\end{array}$ \\
\hline Dpj & $\begin{array}{l}\text { Average duration of car parking in } \\
\text { minutes }\end{array}$ & $\begin{array}{l}\text { Out of } 3 \text { hours and } 45 \text { minutes, } 48 \text { minutes are spend driving, hence } 177 \text { minutes are spent on } \\
\text { parking. }\end{array}$ \\
\hline $\boldsymbol{P}_{i j}$ & $\begin{array}{l}\text { Number of sharing points for } \mathrm{j}=1,2 \\
\text { (car, bicycle) }\end{array}$ & $\begin{array}{l}\text { Company } \mathrm{X} \text { currently has } 4 \text { car sharing points and } 2 \text { bicycle sharing points. Maximum number of car } \\
\text { sharing points is limited by } 740 \mathrm{HDB} \text { carparks and } 1020 \text { public carparks. Bicycle sharing points } \\
\text { limited by bicycle parking spaces at } 131 \text { train stations, } 37 \text { bus interchanges and } 740 \mathrm{HDB} \text { bicycle } \\
\text { parking spaces. }\end{array}$ \\
\hline$P_{i 2}$ & Cost of sharing point & $\begin{array}{l}\text { Estimated using the average monthly parking rate of } \$ 270.57 \text { multiplied by the number of cars. } \\
\text { Bicycle sharing point fee is assumed to be negligible. }\end{array}$ \\
\hline$V_{p i j}$ & $\begin{array}{l}\text { Planned vehicle fleet size for } \mathrm{j}=1,2 \\
\text { (car, bicycle) }\end{array}$ & \\
\hline$V a_{i j}$ & $\begin{array}{l}\text { Actual vehicle fleet size for } \mathrm{j}=1,2 \text { (car, } \\
\text { bicycle) }\end{array}$ & \\
\hline$\theta$ & Vehicle to member ratio & \\
\hline$\theta_{c i}$ & Car to member ratio & \\
\hline$\theta_{b i}$ & Bike to member ratio & \\
\hline$s_{i}$ & Interest coverage ratio & \\
\hline$d_{i}$ & Debt service coverage ratio & \\
\hline$V_{c i}$ & Number of cars purchased & \\
\hline$V_{a}$ & $\begin{array}{l}\text { Actual vehicle fleet size for } j=1,2 \text { (car, } \\
\text { bicycle) }\end{array}$ & \\
\hline$V_{r i j}$ & $\begin{array}{l}\text { Average number of vehicles to } \\
\text { rebalance }\end{array}$ & \\
\hline$E_{b i}$ & $\begin{array}{l}\text { Actual number of employees to } \\
\text { rebalance }\end{array}$ & \\
\hline $\boldsymbol{E}_{d i}$ & Ideal number of employees to rebalance & \\
\hline$N P V$ & Net Present value & \\
\hline$N$ & Length of study period (years) & \\
\hline$r$ & dicount rate & \\
\hline$\mu$ & Mean & \\
\hline$\sigma$ & Standard Deviation & \\
\hline$\tau$ & Fixed percentage of the mean & \\
\hline$F_{i}$ & Actual fleet size in year $i$ & \\
\hline$s_{c i}$ & Competitors debt service issue & \\
\hline$d_{c i}$ & $\begin{array}{l}\text { Competitors debt service coverage } \\
\text { ration }\end{array}$ & \\
\hline$r$ & Registration fees & \\
\hline$p j$ & $\begin{array}{l}\text { Usage fare for service } \mathrm{j}=1,2,3 \text { (car, } \\
\text { bicycle, shuttle) }\end{array}$ & \\
\hline$c j$ & $\begin{array}{l}\text { Cancellation/no show charge for } \mathrm{j}=1,2 \text {, } \\
3 \text { (car, bicycle, shuttle) }\end{array}$ & \\
\hline$v i$ & $\begin{array}{l}\text { Percentage of car fllet size used for } \\
\text { shuttle service }\end{array}$ & \\
\hline$t$ & Number of taxis in Singapore & \\
\hline$k$ & $\begin{array}{l}\text { Number of yearly taxi rides in } \\
\text { Singapore }\end{array}$ & \\
\hline 1 & Cost of leasing & \\
\hline$w$ & Average wage per employee & \\
\hline$e$ & Cost of electricity & $\begin{array}{l}\text { Amount of electricity used per minute (car) } 4.4 \mathrm{kwh} 9 \text { (quoted) and per minute (bicycle) } 0.36 \mathrm{kwh} 10 \\
\text { (quoted) }\end{array}$ \\
\hline$m v$ & Cost of maintenance per vehicle & $\begin{array}{l}\text { Assumes cars have to be serviced once a year and that the repair of eCars is } 8.5 \% \text { more expensive } \\
\text { than the repair of normal car }(\$ 550) \text { or } \$ 600 \text { per eCar per year. Bicycle maintenance is estimated at } \\
\$ 70 \text { per bike per year [Brown } 2013 \text { ] }\end{array}$ \\
\hline$h$ & Insurance premium & Estimated yearly premium of $\$ 185$ per car \\
\hline$m p$ & Maintenance cost per sharing point & \\
\hline$u$ & Utilities cost per head & \\
\hline$f$ & Licensing fee per sharing point & Zero with the assumption that Smove is supported by the relevant authorities \\
\hline$\pi j$ & Vehicle price for $\mathrm{j}=1,2$ (cars, bicycles) & Car price is $\$ 50,000$ (quoted), $\$ 77,000$ (quoted from LTA). Bicycle price is $\$ 1,300$ (quoted). \\
\hline$u E_{o i}$ & Cost of office operations & Estimated rental space for 3 employees in Singapore is $\$ 3000$ per month. \\
\hline$Q_{i}$ & Cost of Marketing & $\$ 126$ for every 2000 flyers distributed. \\
\hline$\gamma$ & Indifference point & \\
\hline
\end{tabular}




\begin{tabular}{|c|c|c|}
\hline Symbol & Parameter & Estimation \\
\hline$V_{i}$ & Net value & \\
\hline $\boldsymbol{R}_{i}$ & Revenue & \\
\hline$C_{i}$ & Operating cost & \\
\hline$I_{i}$ & Net investments & \\
\hline$\overline{T_{i}}$ & Income tax & Based on current Singapore rates \\
\hline$M_{i}$ & Number of members in year i & $\begin{array}{l}\text { Initial number of registrants of 1,029 based on current member total. The maximum } \\
\text { registrants estimated using } 1 \% \text { of total number of car owners in Singapore. }\end{array}$ \\
\hline $\boldsymbol{R}$ & $\begin{array}{l}\text { Upper bound on the number of } \\
\text { members }\end{array}$ & \\
\hline$\alpha$ & Translate parameter & \\
\hline $\boldsymbol{\beta}$ & Sharpness parameter & \\
\hline$B_{i j}$ & $\begin{array}{l}\text { Number of bookings per vehicle } \\
\text { for service, } \mathrm{j}-1,2 \text { (car and } \\
\text { bicycle) }\end{array}$ & $\begin{array}{l}\text { Based on City CarShare (San Francisco) average yearly bookings ( } 790) \text { per vehicle in its } \\
\text { first five years. Maximum number of bookings assumes } 3 \text { bookings per } 12 \text { hours of } \\
\text { operation. Bicycle yearly bookings }(1,310) \text { based on Velib (Paris) first year operation. } \\
\text { Maximum bookings assumes } 16 \text { total bookings per } 12 \text { hour span. }\end{array}$ \\
\hline$S_{i}$ & $\begin{array}{l}\text { Number of bookings for shuttle } \\
\text { service }\end{array}$ & $\begin{array}{l}\text { Assumed that out of the Singapore average total monthly taxi rides of } 21 \text { million, } \\
\text { Company X would share the equivalent of the proportion of its car fleet size to the total } \\
\text { fleet size owned by all taxi companies in Singapore which is } 27,703 \text {. }\end{array}$ \\
\hline Duj & $\begin{array}{l}\text { Average duration of use in } \\
\text { minutes for } \mathrm{j}=1,2,3 \text { (car, bicycle, } \\
\text { shuttle) }\end{array}$ & $\begin{array}{l}\text { Based on City CarShare case study, out of } 3 \text { hours and } 45 \text { minutes average booking } \\
\text { duration, customers generally drive for } 20 \text { miles. Assuming average car speed of } 25 \mathrm{mph} \text {, } \\
\text { the average duration of driving per booking is } 48 \text { minutes. For bikes assumes average ride } \\
\text { duration of } 25 \% \text { of maximum battery distance. Shuttle is based on average taxi ride } \\
\text { duration of } 22 \text { minutes. }\end{array}$ \\
\hline$D p j$ & $\begin{array}{l}\text { Average duration of car parking } \\
\text { in minutes }\end{array}$ & $\begin{array}{l}\text { Out of } 3 \text { hours and } 45 \text { minutes, } 48 \text { minutes are spend driving, hence } 177 \text { minutes are spent } \\
\text { on parking. }\end{array}$ \\
\hline $\boldsymbol{P}_{i j}$ & $\begin{array}{l}\text { Number of sharing points for } \mathrm{j}=1 \text {, } \\
2 \text { (car, bicycle) }\end{array}$ & $\begin{array}{l}\text { Company X currently has } 4 \text { car sharing points and } 2 \text { bicycle sharing points. Maximum } \\
\text { number of car sharing points is limited by } 740 \text { HDB carparks and } 1020 \text { public carparks. } \\
\text { Bicycle sharing points limited by bicycle parking spaces at } 131 \text { train stations, } 37 \text { bus } \\
\text { interchanges and } 740 \text { HDB bicycle parking spaces. }\end{array}$ \\
\hline$P_{i 2}$ & Cost of sharing point & $\begin{array}{l}\text { Estimated using the average monthly parking rate of } \$ 270.57 \text { multiplied by the number of } \\
\text { cars. Bicycle sharing point fee is assumed to be negligible. }\end{array}$ \\
\hline$V_{p i j}$ & $\begin{array}{l}\text { Planned vehicle fleet size for } \mathrm{j}=1 \text {, } \\
2 \text { (car, bicycle) }\end{array}$ & \\
\hline$V a_{i j}$ & $\begin{array}{l}\text { Actual vehicle fleet size for } \mathrm{j}=1,2 \\
\text { (car, bicycle) }\end{array}$ & \\
\hline$\theta$ & Vehicle to member ratio & \\
\hline$\theta_{c i}$ & Car to member ratio & \\
\hline $\boldsymbol{\theta}_{b i}$ & Bike to member ratio & \\
\hline$s_{i}$ & Interest coverage ratio & \\
\hline$d_{i}$ & Debt service coverage ratio & \\
\hline$V_{c i}$ & Number of cars purchased & \\
\hline$V_{a}$ & $\begin{array}{l}\text { Actual vehicle fleet size for } \mathrm{j}=1,2 \\
\text { (car, bicycle) }\end{array}$ & \\
\hline$V_{r i j}$ & $\begin{array}{l}\text { Average number of vehicles to } \\
\text { rebalance }\end{array}$ & \\
\hline $\boldsymbol{E}_{b i}$ & $\begin{array}{l}\text { Actual number of employees to } \\
\text { rebalance }\end{array}$ & \\
\hline $\boldsymbol{E}_{d i}$ & $\begin{array}{l}\text { Ideal number of employees to } \\
\text { rebalance }\end{array}$ & \\
\hline$N P V$ & Net Present value & \\
\hline$N$ & Length of study period (years) & \\
\hline$r$ & discount rate & \\
\hline$\mu$ & Mean & \\
\hline$\sigma$ & Standard Deviation & \\
\hline$\tau$ & Fixed percentage of the mean & \\
\hline $\boldsymbol{F}_{i}$ & Actual fleet size in year $i$ & \\
\hline$S_{c i}$ & Competitors debt service issue & \\
\hline$d_{c i}$ & $\begin{array}{l}\text { Competitors debt service } \\
\text { coverage ration }\end{array}$ & \\
\hline$r$ & Registration fees & \\
\hline$p j$ & $\begin{array}{l}\text { Usage fare for service } \mathrm{j}=1,2,3 \\
\text { (car, bicycle, shuttle) }\end{array}$ & \\
\hline
\end{tabular}


Systems Engineering

\begin{tabular}{|c|c|c|}
\hline$c j$ & $\begin{array}{l}\text { Cancellation/no show charge for } \\
\mathrm{j}=1,2,3 \text { (car, bicycle, shuttle) }\end{array}$ & \\
\hline$v i$ & $\begin{array}{l}\text { Percentage of car fleet size used } \\
\text { for shuttle service }\end{array}$ & \\
\hline$t$ & Number of taxis in Singapore & \\
\hline $\boldsymbol{k}$ & $\begin{array}{l}\text { Number of yearly taxi rides in } \\
\text { Singapore }\end{array}$ & \\
\hline l & Cost of leasing & \\
\hline$w$ & Average wage per employee & \\
\hline$e$ & Cost of electricity & $\begin{array}{l}\text { Amount of electricity used per minute (car) } 4.4 \text { kwh9 (quoted) and per minute (bicycle) } \\
0.36 \text { kwh10 (quoted) }\end{array}$ \\
\hline$m v$ & Cost of maintenance per vehicle & $\begin{array}{l}\text { Assumes cars have to be serviced once a year and that the repair of eCars is } 8.5 \% \text { more } \\
\text { expensive than the repair of normal car }(\$ 550) \text { or } \$ 600 \text { per eCar per year. Bicycle } \\
\text { maintenance is estimated at } \$ 70 \text { per bike per year [Brown 2013] }\end{array}$ \\
\hline $\boldsymbol{h}$ & Insurance premium & Estimated yearly premium of $\$ 185$ per car \\
\hline$m p$ & $\begin{array}{l}\text { Maintenance cost per sharing } \\
\text { point }\end{array}$ & \\
\hline$u$ & Utilities cost per head & \\
\hline$f$ & Licensing fee per sharing point & Zero with the assumption that Smove is supported by the relevant authorities \\
\hline$\pi j$ & $\begin{array}{l}\text { Vehicle price for } \mathrm{j}=1,2 \text { (cars, } \\
\text { bicycles) }\end{array}$ & $\begin{array}{l}\text { Car price is } \$ 50,000 \text { (quoted), } \$ 77,000 \text { (quoted from LTA). Bicycle price is } \$ 1,300 \\
\text { (quoted). }\end{array}$ \\
\hline$u E_{o i}$ & Cost of office operations & Estimated rental space for 3 employees in Singapore is $\$ 3000$ per month. \\
\hline$\overline{Q_{i}}$ & Cost of Marketing & $\$ 126$ for every 2000 flyers distributed. \\
\hline $\mathbf{T}$ & Indifference point & \\
\hline
\end{tabular}


Table V. DCF MATHEMATICAL MODELLING

\begin{tabular}{|c|c|}
\hline DCF Component & ulae \\
\hline $\begin{array}{l}\text { Revenues }\left(R_{i}\right): \\
\text { Registration fees } \\
\text { Car usage charge } \\
\text { Bicycle usage charge } \\
\text { Shuttle usage charge }\end{array}$ & $\begin{array}{l}r\left(M_{i}-M_{i-1}\right) \\
p_{1} D_{i 1} B_{i 1}\left(V_{\text {ail }}-V_{\text {ril }}+3 E_{b i}\right)\left(I-v_{j}\right) \\
p_{2} D_{i 2} B_{i 2}\left(\operatorname{Va}_{i 2}-V r_{i 2}+3 E_{b i}\right) \\
p_{3} D_{i 3} S_{i} \text { where } S i=\left(V_{\text {ail }}-V_{r i 1}+3 E_{b i}\right)\left(v_{i} / t\right) k\end{array}$ \\
\hline $\begin{array}{l}\text { Operating Costs }\left(C_{i}\right): \\
\text { Car leasing } \\
\text { Manpower } \\
\text { Electricity } \\
\text { Vehicle maintenance } \\
\text { Insurance premium } \\
\text { Sharing point operations } \\
\text { Office operations } \\
\text { Marketing }\end{array}$ & $\begin{array}{l}l\left(V_{a i l}-V_{c i}\right) \\
w\left(E_{b i}+E_{o i}\right) \\
\sum_{j} e D_{i j} B_{i j}\left(V_{a i j}-V_{r i j}+3 E_{b i}\right) \\
m_{v} \sum_{j j} V_{a i j} \\
h V_{a i l} \\
m_{p} \sum_{j} P_{i j} \\
u E_{o i} \\
Q_{i}\end{array}$ \\
\hline $\begin{array}{l}\text { Net Investments }\left(I_{i}\right): \\
\text { Sharing point licensing fees } \\
\text { Vehicle purchase } \\
\text { Technology }\end{array}$ & $\begin{array}{l}f \sum_{j} P_{i j} \\
\pi_{1}\left(V_{c i} j\right)+\pi_{2}\left(V_{a i 2}\right) \\
Z_{i}\end{array}$ \\
\hline Income Tax $\left(T_{i}\right)$ & $\begin{array}{l}\text { For } i=1,2,3: \\
\left\{\begin{array}{r}0 \text { if } R_{i}-O_{i}<100,000 \\
0.17 * 0.5 *\left(R_{i}-O_{i}\right) \text { if } 100,000 \leq R_{i}-O_{i}<300,000 \\
\left(100,000+\left(R_{i}-O_{i}-200,000\right)\right) * 0.17 \text { if } R_{i}-O_{i} \geq 300,000\end{array}\right. \\
\text { For } i=4,5, \ldots 20: \\
\left\{\begin{array}{r}0 \text { if } R_{i}-O_{i}<0 \\
0.17 * 0.75 *\left(R_{i}-O_{i}\right) \text { if } 0 \leq R_{i}-O_{i}<10,000 \\
0.17 * 0.5 *\left(R_{i}-O_{i}\right) \text { if } 10,000 \leq R_{i}-O_{i}<290,000 \\
\left(45,000+\left(R_{i}-O_{i}-300,000\right)\right) * 0.17 \text { if } R_{i}-O_{i} \geq 300,000\end{array}\right.\end{array}$ \\
\hline
\end{tabular}




\begin{tabular}{|c|c|}
\hline DCF Component & Formulae \\
\hline $\begin{array}{l}\text { Revenues }\left(\boldsymbol{R}_{i}\right) \text { : } \\
\text { Registration fees } \\
\text { Car usage charge } \\
\text { Bicycle usage charge } \\
\text { Shuttle usage charge }\end{array}$ & $\begin{array}{l}r\left(M_{i}-M_{i-1}\right) \\
p_{1} D_{i 1} B_{i 1}\left(V_{a i 1}-V_{r i 1}+3 E_{b i}\right)\left(1-v_{i}\right) \\
p_{2} D_{i 2} B_{i 2}\left(V a_{i 2}-V r_{i 2}+3 E_{b i}\right) \\
p_{3} D_{i 3} S_{i} \text { where } S i=\left(V_{a i l}-V_{r i l}+3 E_{b i}\right)\left(v_{i} / t\right) k\end{array}$ \\
\hline $\begin{array}{l}\text { Operating Costs }\left(C_{i}\right) \text { : } \\
\text { Car leasing } \\
\text { Manpower } \\
\text { Electricity } \\
\text { Vehicle maintenance } \\
\text { Insurance premium } \\
\text { Sharing point operations } \\
\text { Office operations } \\
\text { Marketing }\end{array}$ & $\begin{array}{l}l\left(V_{a i l}-V_{c i}\right) \\
w\left(E_{b i}+E_{o i}\right) \\
\sum_{j} e D_{i j} B_{i j}\left(V_{a i j}-V_{r i j}+3 E_{b i}\right) \\
m_{v} \sum_{j} V_{a i j} \\
h V_{a i l} \\
m_{p} \sum_{j} P_{i j} \\
u E_{o i} \\
Q_{i}\end{array}$ \\
\hline $\begin{array}{l}\text { Net Investments }\left(\boldsymbol{I}_{i}\right) \text { : } \\
\text { Sharing point licensing fees } \\
\text { Vehicle purchase } \\
\text { Technology }\end{array}$ & $\begin{array}{l}f \sum_{j} P_{i j} \\
\pi_{1}\left(V_{c i}\right)+\pi_{2}\left(V_{a i 2}\right) \\
Z_{i}\end{array}$ \\
\hline Income Tax $\left(T_{i}\right)$ & $\begin{array}{l}\text { For } i=1,2,3: \\
\left\{\begin{array}{r}0 \text { if } R_{i}-O_{i}<100,000 \\
0.17 * 0.5 *\left(R_{i}-O_{i}\right) \text { if } 100,000 \leq R_{i}-O_{i}<300,000 \\
\left(100,000+\left(R_{i}-O_{i}-200,000\right)\right) * 0.17 \text { if } R_{i}-O_{i} \geq 300,000\end{array}\right. \\
\text { For } i=4,5, \ldots 20: \\
\left\{\begin{array}{r}0 \text { if } R_{i}-O_{i}<0 \\
0.17 * 0.75 *\left(R_{i}-O_{i}\right) \text { if } 0 \leq R_{i}-O_{i}<10,000 \\
0.17 * 0.5 *\left(R_{i}-O_{i}\right) \text { if } 10,000 \leq R_{i}-O_{i}<290,000 \\
\left(45,000+\left(R_{i}-O_{i}-300,000\right)\right) * 0.17 \text { if } R_{i}-O_{i} \geq 300,000\end{array}\right.\end{array}$ \\
\hline
\end{tabular}

Table VI. MARKET DEMAND

\begin{tabular}{|c|c|c|c|}
\hline S-curve Paremeters & $M_{i}$ & $B_{i 1}$ & $B_{i 2}$ \\
\hline$R$ & 50,000 & 1.095 & 1,310 \\
\hline$\alpha$ & 47.6 & 0.386 & 3.46 \\
\hline$\beta$ & 0.5 & 0.08 & 0.05 \\
\hline
\end{tabular}

\begin{tabular}{|c|c|c|c|}
\hline S-curve Parameters & $M_{i}$ & $B_{i 1}$ & $B_{i 2}$ \\
\hline $\boldsymbol{R}$ & $\mathbf{5 0 , 0 0 0}$ & $\mathbf{1 . 0 9 5}$ & $\mathbf{1 , 3 1 0}$ \\
\hline$\alpha$ & 47.6 & $\mathbf{0 . 3 8 6}$ & $\mathbf{3 . 4 6}$ \\
\hline $\boldsymbol{\beta}$ & 0.5 & 0.08 & 0.05 \\
\hline
\end{tabular}


Table VII. SHARING POINTS

\begin{tabular}{|c|c|c|}
\hline S-curve Parameters & $\boldsymbol{P}_{i 1}$ & $\boldsymbol{P}_{i 2}$ \\
\hline $\boldsymbol{R}$ & 300 & 908 \\
\hline$\alpha$ & 0.386 & 3.46 \\
\hline$\beta$ & 0.5 & 0.5 \\
\hline
\end{tabular}

\begin{tabular}{|c|c|c|}
\hline S-curve Parameters & $\boldsymbol{P}_{i 1}$ & $\boldsymbol{P}_{i 2}$ \\
\hline $\boldsymbol{R}$ & 300 & 908 \\
\hline$\alpha$ & 0.386 & 3.46 \\
\hline$\beta$ & 0.5 & 0.5 \\
\hline
\end{tabular}

Table VIII. FORECAST ERROR

\begin{tabular}{|c|c|c|c|c|c|}
\hline \multirow{2}{*}{ Parameter } & \multicolumn{5}{c|}{ Amount of Errors } \\
& $\boldsymbol{M}_{\boldsymbol{i}}$ & $\boldsymbol{B}_{\boldsymbol{i} 1}$ & $\boldsymbol{B}_{\boldsymbol{i} 2}$ & $\boldsymbol{P}_{\boldsymbol{i} 1}$ & $\boldsymbol{P}_{\boldsymbol{i} 2}$ \\
\hline Initial value & $20 \%$ & $\mathbf{1 0 \%}$ & $\mathbf{1 0 \%}$ & - & - \\
\hline $\boldsymbol{R}$ & $\mathbf{2 0 \%}$ & $\mathbf{2 0 \%}$ & $\mathbf{4 0 \%}$ & $\mathbf{4 0 \%}$ & $\mathbf{4 0 \%}$ \\
\hline $\boldsymbol{\beta}$ & $\mathbf{4 0 \%}$ & $\mathbf{4 0 \%}$ & $\mathbf{4 0 \%}$ & $\mathbf{4 0 \%}$ & $\mathbf{4 0 \%}$ \\
\hline
\end{tabular}

\begin{tabular}{|c|c|c|c|c|c|}
\hline \multirow{2}{*}{ Parameter } & \multicolumn{5}{c|}{ Amount of Errors } \\
& $\boldsymbol{M}_{\boldsymbol{i}}$ & $\boldsymbol{B}_{\boldsymbol{i} 1}$ & $\boldsymbol{B}_{\boldsymbol{i} 2}$ & $\boldsymbol{P}_{\boldsymbol{i} 1}$ & $\boldsymbol{P}_{\boldsymbol{i} 2}$ \\
\hline Initial value & $\mathbf{2 0 \%}$ & $\mathbf{1 0 \%}$ & $\mathbf{1 0 \%}$ & - & - \\
\hline $\boldsymbol{R}$ & $\mathbf{2 0 \%}$ & $\mathbf{2 0 \%}$ & $\mathbf{4 0 \%}$ & $\mathbf{4 0 \%}$ & $\mathbf{4 0 \%}$ \\
\hline $\boldsymbol{\beta}$ & $\mathbf{4 0 \%}$ & $\mathbf{4 0 \%}$ & $\mathbf{4 0 \%}$ & $\mathbf{4 0 \%}$ & $\mathbf{4 0 \%}$ \\
\hline
\end{tabular}


Table IX. COMPARISON OF PERFORMANCE METRICS UNDER DIFFERENT DESIGNS

\begin{tabular}{lccccc}
\hline NPV $(\$)$ & $\begin{array}{c}\text { Base } \\
\text { Case } \\
(1)\end{array}$ & $\begin{array}{c}\text { Flexible } \\
\text { Expansion } \\
(2)\end{array}$ & $\begin{array}{c}\text { Flexible } \\
\text { Rebalancing } \\
(3)\end{array}$ & $\begin{array}{c}\text { Combined } \\
\text { Design } \\
(4)\end{array}$ & $\begin{array}{c}\text { Best } \\
\text { Design }\end{array}$ \\
\hline Mean & $(1,078,806)$ & $(773,252)$ & $\mathbf{6 , 9 4 3 , 3 7 3}$ & $\mathbf{6 , 3 2 0 , 0 3 3}$ & $(3)$ \\
\hline Min & $(17,902,676)$ & $(15,847,924)$ & $(6,080,083)$ & $(10,274,524)$ & $(3)$ \\
\hline Max & $\mathbf{1 6 , 4 2 7 , 6 2 0}$ & $\mathbf{1 5 , 6 9 1 , 5 5 5}$ & $\mathbf{2 1 , 6 3 4 , 1 7 4}$ & $\mathbf{2 2 , 0 0 7 , 4 9 2}$ & $(4)$ \\
\hline VAR & $(\mathbf{7 , 1 9 4 , 7 5 9 )}$ & $(\mathbf{7 , 0 8 0 , 5 5 0 )}$ & $\mathbf{1 , 1 9 9 , 6 6 6}$ & $\mathbf{4 8 6 , 1 8 3}$ & $(3)$ \\
$(\mathbf{1 0 \%})$ & $\mathbf{5 , 3 6 6 , 8 1 7}$ & $\mathbf{5 , 4 2 7 , 8 1 8}$ & $\mathbf{1 2 , 6 1 7 , 4 6 2}$ & $\mathbf{1 2 , 1 3 4 , 2 4 8}$ & $(3)$ \\
\hline $\begin{array}{l}\text { VAG } \\
(\mathbf{9 0 \%})\end{array}$ & $\mathbf{4 , 9 1 3 , 4 1 5}$ & $\mathbf{4 , 7 8 6 , 9 4 3}$ & $\mathbf{4 , 4 5 8 , 4 0 1}$ & $\mathbf{4 , 5 4 9 , 5 1 4}$ & $(3)$ \\
\hline S. D. & - & - & 100,000 & 100,000 & $(2)$ \\
\hline $\begin{array}{l}\text { Additional } \\
\text { CAPEX }\end{array}$ & - & $\mathbf{3 0 5 , 5 5 4}$ & $\mathbf{8 , 0 2 2 , 1 7 9}$ & $\mathbf{7 , 3 9 8 , 8 3 9}$ & $(3)$ \\
\hline $\begin{array}{l}\text { Value of } \\
\text { Flexibility }\end{array}$ & - & & & \\
\hline
\end{tabular}

